\title{
Experimental studies on linguistic processing: a review of different experiences and their contributions
}

\author{
Camila STECHER (D) \\ University of Buenos Aires (IL/FFYL/UBA)
}

\section{ABSTRACT}

This conference gathered three dissertations that had in common the performance of experimental research that provided substantial evidence to understand the processes and the representations that lie behind different linguistic domains and abilities, as well as the brain activity that sustains them. Dr. Adolfo García presented original experimental research about the neural organization of the semantic knowledge, performed mainly with electroencephalography and magnetoencephalography. Dr.

María Elina Sánchez presented a study developed with Dr. Virginia Jaichenco in which they analyzed, through behavioral and eye tracking methods, the sentence reading performance in people with acquired dyslexia and a control group of people with no linguistic disorders. Dr. Yamila Sevilla presented a work in which she analyzed the asymmetry that emerges in the comprehension of subject and object relative clauses with psychological predicates, using behavioral and pupillometry methods.

\section{RESUMEN}

Esta mesa reúne tres presentaciones que tienen como eje común la realización de trabajos experimentales que aportan evidencia sustancial para comprender los procesos y las representaciones que subyacen a distintos dominios y habilidades lingüísticas, así como la actividad cerebral que los sustenta. Primero, el Dr. Adolfo García presentó investigaciones experimentales originales, realizadas principalmente con electroencefalografía y 


\section{REVISTA DA ABRALIN}

magnetoencefalografía, acerca de la organización neural del conocimiento semántico. Luego, la Dra. María Elina Sánchez expuso un estudio realizado con la Dra. Virginia Jaichenco en el que analizaron, mediante técnicas conductuales y de seguimiento de movimientos oculares, la lectura de oraciones por parte de sujetos con dislexia adquirida y un grupo control de sujetos sin dificultades. Por último, la Dra. Yamila Sevilla introdujo una investigación en la que se analizó, con datos comportamentales y de pupilometría en español, la asimetría en la comprensión de oraciones relativas de sujeto y de objeto en predicados psicológicos.

\section{KEYWORDS}

Experimental methods. Psycholinguistics. Neurolinguistics.

\section{PALAVRAS CLAVE}

Metodologías experimentales. Psicolingüística. Neurolingüística.

The roundtable Experimental methods on language processing was co-organized by the Associação Brasileira de Linguística (ABRALIN) and the Sociedad Argentina de Estudios Lingüísticos (SAEL). The participants were Adolfo García, María Elina Sánchez (standing for Virginia Jaichenco who was unable to participate because of health-related issues) and Yamila Sevilla. The common theme of this table was the discussion of experimental research that provides substantial evidence to understand the processes and the representations that lie behind different linguistic domains and abilities, as well as the brain activity that sustains them.

Dr. García is co-director of the Cognitive Neuroscience Center of the Universidad de San Andrés, Atlantic Fellow of the Global Brain Health Institute of the University of California, researcher at CONICET and director of the Masters in Language and Cognition in the Universidad Nacional de Cuyo (UnCuyo). His work was titled Semochronometry: a neuroscientific view on the temporal flow of verbal meaning and it dealt with the neural organization of the semantic knowledge, specifically on how the meaning flows in neural time. He explained that when we listen to a word, it can bring forward two types of semantic information, that are processed by two partially dissociable cerebral networks: modality-specific information, that's processed by the embodied systems, and multimodal associations, processed by the conceptual systems. The aim of his research was to find which of these systems was activated first when hearing a word. To assess this, he conducted two studies.

In the first one, performed with magnetoencephalography (MEG), the participants were asked to perform a lexical decision task (determining whether the input was a word or not), with stimuli that included action verbs, abstract verbs and pseudo words that resembled Spanish verbs. They found a differential neural activation of the motor circuits of the participants (that correspond to 


\section{REVISTA DA ABRALIN}

the embodied systems of semantic processing) between the processing of action verbs and abstract verbs at a very early stage $(150 \mathrm{~ms})$. In comparison, the regions corresponding to the multimodal systems (the anterior temporal lobe and the inferior parietal cortex) showed that same discrimination much later (400ms). In the second one, performed with electroencephalography (EEG) and intracranial electroencephalography (IEEG), the participants were shown different words, that denoted parts of the face and other body parts, and were asked to say if they were related to the face or not. These stimuli were selected because face recognition has a distinctive cerebral time print on N170. Therefore, when a significantly greater modulation was found for face parts in this study, it was possible to construe that there was evidence that face-related words have the possibility to recruit canonical mechanisms of the processing of real faces in a distinctive way.

The sum of the results of both experiments works as evidence that the reactivation of the modality-specific circuits and their modality-specific associations by words are fast (occur before $200 \mathrm{~ms}$ ) and primary, even when there is no explicit semantic access. Thus, it can be stated that the embodied systems have a distinctive and primary role in the flow of meaning.

Dr. Sánchez is a neurolinguistics professor in the Faculty of Philosophy and Letters of the Universidad de Buenos Aires and has dictated graduate courses in the same school, as well as in the Faculty of Psychology and in UnCuyo. She has a postdoctoral scholarship financed by the Consejo Nacional de Investigaciones Científicas y Técnicas (CONICET) in the Linguistics Institute (UBA). Dr. Jaichenco is a Psycholinguistics and Neurolinguistics professor in the Faculty of Philosophy and Letters of the Universidad de Buenos Aires, where she is also the director of the specialization in Cognitive Neuroscience of Language and Reading, as well as in the Faculty of Psychology (UBA) and in UnCuyo. She is the director of the psycho and neurolinguistics research team in the Linguistics Institute (UBA).

In their work, Reading, acquired dyslexia and eye-tracking, they analyzed the sentence reading performance by a group of people with acquired dyslexia and a control group of healthy people. Parting from the dual-route model (Coltheart, 2007), Sánchez explained that there are two mechanisms for word-reading: a lexical route, that's activated when a word in the orthographic input lexicon is recognized; and a non-lexical route, that applies the grapheme-phoneme rules. This model allows us to recognize three types of acquired dyslexia, that are alterations that impact specifically the reading process following a brain injury.

For this study, they worked with a group of people with acquired phonological dyslexia, that corresponds to an alteration in the non-lexical route and generates a deficit in the reading of new words and pseudo words. This group, along with a group of healthy control people, were asked to perform a task of sentence reading while they were being monitored by an eye-tracking system. This method allows researchers to observe, in detail, the actions that are being performed by the subjects when they are reading: where the fixations occur and for how long, the length of the saccades, the skipping pattern and whether there are regressions. It also provides information on the processing cost of the stimuli, since it modulates the variability of the fixations and the saccades: a higher difficulty brings longer fixations and shorter saccades (and vice versa). 


\section{REVISTA DA ABRALIN}

They found that people with acquired dyslexia showed a particular reading behavior, characterized by longer fixation times (that were concentrated on the beginning of the words), less skipping and a regressive and progressive refixation pattern, in comparison to their control counterparts, who showed a progressive pattern, with less fixations and adjusted the points of fixation according to the length of the word. Last, they found a participant of the group of people with acquired dyslexia that showed a significantly different behavior to the rest, with a highly regressive conduct, an abnormal skipping pattern and whose fixations were concentrated on the final end of the words. This finding, of differential behavior among people with the same diagnosis, confirms the importance of working with multiple experimental research methods, since that allows researchers to extract detailed behavioral profiles, that can then be translated into more precise guidelines when planning the rehabilitation strategies for each patient.

Dr. Sevilla is an adjunct researcher at CONICET in the Linguistics Institute (UBA), professor of neurolinguistics in the Faculty of Philosophy and Letters (UBA) and she's dictated many undergraduate and graduate courses on psycho and neurolinguistics in several national universities in Argentina. In her work, Revisiting the processing of relative clauses. The case of psychological predicates in Spanish, she studied the asymmetry that exists among the comprehension of object and subject relative clauses with psychological predicates.

She explained that, in action predicates, the subject relative clauses show greater ease for processing, while object relative clauses cause more production errors and difficulties, longer reaction times in comprehension tasks and are acquired later in development. This asymmetry is due mainly to the linear or structural distance that stands between the elements that are to be put in relation, that causes a decay of their activation in the working memory. Instead, in psychological predicates in Spanish the structure projected is different, provoking that the distance that separates the elements in relation to have an inverted pattern to that of the agentive predicates, and allowing researchers to predict that the processing cost should also show an inverted pattern. She presented a study (MURUJOSA et al., 2020) in which participants were asked to perform an auditory sentence comprehension task involving agentive and psychological predicates with subject and object relative clauses, while the researchers measured their right answers, reaction times and pupil diameters.

The results confirmed the predictions previously presented. The subject relative clauses were answered more precisely and within shorter times with agentive than with psychological predicates, with an inverted pattern for object relative clauses. The pupil diameter analysis showed the same trends for the processing costs of the stimuli. These findings stand as evidence that there are distance and interference effects during the recovery of elements from the working memory when processing relative clauses and that these effects show an inverted pattern when processing relative clauses with psychological predicates instead of agentive predicates.

The different studies that were presented in this roundtable highlight the great relevance that the different experimental methods have for the study of language processing and the particularities of the different languages, whose findings can be applied both in the academic and the clinical fields. 


\title{
REVISTA DA ABRALIN
}

\author{
REFERENCES
}

COLTHEART, Max. Acquired dyslexias and the computational modelling of reading. Cognitive Neuropsychology. Año 23, n. 1, p. 96109, 5 de junio de 2007. https://doi.org/10.1080/02643290500202649

EXPERIMENTAL methods on language processing. Roundtable discussed by Adolfo García, María Elina Sánchez and Yamila Sevilla [n.p.], 2020. 1 video (2h 10min). Published on the YouTube channel of the Associação Brasileira de Linguística. Available at: https://youtu.be/HOAJAFSMG4g. Consulted on june 11th of 2020.

GARCÍA, Adolfo; MOGUILNER, Sebastián; TORQUATI, Kathya; GARCÍA-MARCO, Eduar Herrera; MUÑOZ, Edinson; CASTILLO, Eduardo M.; KLEINESHAY, Tara; SEDEÑO, Lucas; IBÁÑEZ, Agustín. How meaning unfolds in neural time: Embodied reactivations can precede multimodal semantic effects during language processing. NeuroImage. Año 26, n. 197, p. 439-449, 3 de mayo de 2019. https://doi.org/10.1016/j.neuroimage.2019.05.002

MURUJOSA, Marisol; GATTEI, Carolina; SHALOM, Diego; SEVILLA, Yamila. Object relatives are not always more difficult to process, even in Spanish. Evidence from a study of relative clauses comprehension with psychological predicates. Poster - 33rd Annual CUNY Human Sentence Processing Conference, online, 2020. 